\title{
DOSES, FONTES E ÉPOCAS DE APLICAÇÃO DE NITROGÊNIO EM CULTIVARES DE ARROZ
}

\author{
Doses, sources and periods of nitrogen application in rice cultivars
}

\author{
Amanda Hernandes ${ }^{1}$, Salatiér Buzetti², Marcelo Andreotti ${ }^{3}$, Orivaldo Arf $^{2}$, Marco Eustáquio de Sá ${ }^{2}$
}

\begin{abstract}
RESUMO
As exigências das culturas pelo nitrogênio são diferenciadas, tanto no que se refere às quantidades, quanto à época de aplicação, sendo que este nutriente pode ser perdido por lixiviação, volatilização e erosão. Conduziu-se este trabalho, com o objetivo de avaliar a resposta das cultivares de arroz BRSMG Curinga e IAC 202 à aplicação de doses, fontes e épocas de aplicação de nitrogênio. Os tratamentos constituíram-se de cinco doses de nitrogênio $\left(0,50,100,150\right.$ e $\left.200 \mathrm{~kg} \mathrm{de} \mathrm{N} \mathrm{ha}^{-1}\right)$, sob a forma de três fontes nitrogenadas (sulfonitrato de amônio com inibidor de nitrificação, sulfato de amônio e uréia), em duas épocas de aplicação (semeadura ou perfilhamento), cultivado com irrigação suplementar. O delineamento experimental utilizado foi o de blocos ao acaso em esquema fatorial $5 \times 3 \times 2 \times 2$, com quatro repetições. A cultivar de arroz BRSMG Curinga apresentou a maior produtividade. As doses de $\mathrm{N}$ aumentaram o teor de $\mathrm{N}$ foliar, a altura de plantas, o número de panículas $\mathrm{m}^{-2}$, o número e a massa de espiguetas granadas panícula ${ }^{-1}$ e a produtividade de grãos, mas não influenciou a massa de 100 grãos. As fontes nitrogenadas e as épocas de aplicação tiveram efeito semelhante para todas as avaliações. A maior produtividade foi alcançada com a dose de $122 \mathrm{~kg}$ de $\mathrm{N} \mathrm{ha}^{-1}$, independente da fonte utilizada.
\end{abstract}

Termos para indexação: Oryza sativa L., adubação, sulfonitrato de amônio, sulfato de amônio, uréia.

\begin{abstract}
Nitrogen is a nutrient that can be lost through leaching, volatilization and erosion. Crops require nitrogen in different doses and application times. The objective of this work was to evaluate the performance of BRSMG Curinga and IAC 202 rice to application of five doses of nitrogen $\left(0,50,100,150\right.$ and $200 \mathrm{~kg}_{\text {of }} \mathrm{N} \mathrm{ha}^{-1}$ ) using three nitrogen sources (ammonium sulfonitrate with nitrification inhibitor, ammonium sulfate and urea), at two times of application (at sowing or at tillering stage), with sprinkler irrigation. A randomized block design was used in a $5 \times 3 \times 2 \times 2$ factorial scheme, with four repetitions. The Curinga rice showed the highest grain yield. The doses of $\mathrm{N}$ increased the foliar $\mathrm{N}$ content, the height of plants, the number of panicles $\mathrm{m}^{-2}$, the number of full grains panicle ${ }^{-1}$, the mass of full grains per panicle and the grain yield, but did not influence the mass of 100 grains. The time of application and the nitrogen sources had a similar effect in all evaluations. The highest grain yield was reached with a dose of $122 \mathrm{~kg}$ of $\mathrm{N} \mathrm{ha}^{-1}$, regardless of the source.
\end{abstract}

Index terms: Oryza sativa L., fertilization, ammonium sulfonitrate, ammonium sulfate, urea.

(Recebido em 19 de junho de 2008 e aprovado em 30 de julho de 2009)

\section{INTRODUÇÃO}

O arroz é um dos alimentos mais consumidos mundialmente, sendo elemento básico na alimentação da maioria dos povos, e a produtividade final da cultura depende da cultivar utilizada, da quantidade de insumos e das técnicas de manejo empregadas, além do clima. A adubação é um dos fatores que proporciona a demonstração do potencial produtivo da cultura, sendo o nitrogênio um dos elementos essenciais para o crescimento e desenvolvimento das plantas, e um dos nutrientes mais exigidos pelas plantas em praticamente todos os estádios de desenvolvimento da cultura (Marumoto, 1986).

$\mathrm{O} \mathrm{N}$ faz parte das moléculas de clorofila, do citocromo e de todas as enzimas e coenzimas, além de ser elemento constituinte de proteínas e ácidos nucléicos (Malavolta et al., 1997). No arroz, tem papel fundamental na formação da panícula e dos grãos (Barbosa Filho, 1987). O N também estimula o crescimento do sistema radicular do arroz e, consequentemente, favorece o perfilhamento; aumenta o número de espiguetas panícula ${ }^{-1} \mathrm{e}$ a massa de grãos (Fornasieri Filho \& Fornasieri, 1993), assim como o número de panículas $\mathrm{m}^{-2}$ e o número de grãos panícula ${ }^{-1}$ (Husain \& Sharma, 1991).

A utilização de doses, épocas de aplicação (parcelamento ou não) e fontes de $\mathrm{N}$ podem aumentar significativamente a eficiência do uso dos fertilizantes nitrogenados e, consequentemente, a produtividade de culturas anuais, como o arroz (Fageria et al., 2003). Normalmente, a dose de $\mathrm{N}$ a ser utilizada na cultura baseia-

${ }^{1}$ Faculdade de Ciências Agrárias e Veterinária/UNESP - Campus de Jaboticabal - Jaboticabal, SP

${ }^{2}$ Faculdade de Engenharia de Ilha Solteira/UNESP - Departamento de Fitossanidade, Engenharia Rural e Solos Cx.P. 31 - 15.385-000 - Ilha Solteira, SP sbuzetti@agr.feis.unesp.br

${ }^{3}$ Faculdade de Engenharia de Ilha Solteira/UNESP - Campus de Ilha Solteira - Ilha Solteira, SP 
se na produtividade esperada e no histórico da área. Aliado a este fato, a crescente utilização de cultivares de alto potencial produtivo tem implicado no uso mais frequente de insumos, dentre os quais o N. No entanto, a utilização de doses cada vez mais elevadas deste nutriente para aumentar a produtividade pode acarretar em elevado desenvolvimento vegetativo, dependendo da cultivar, o que pode levar ao acamamento de plantas e interferir negativamente na produtividade e na qualidade dos grãos (Campello Junior, 1985), além de dificultar a operação de colheita. No arroz irrigado por aspersão, como o N é passível de lixiviação, a aplicação de doses mais elevadas em determinados estádios fenológicos poderá proporcionar ganhos marcantes de produtividade.

Desse modo, o trabalho objetivou avaliar o efeito de cinco doses de $\mathrm{N}$ e três fontes de fertilizantes nitrogenados, em duas épocas de aplicação, nas cultivares de arroz BRSMG Curinga e IAC 202, cultivadas com irrigação suplementar.

\section{MATERIAL E MÉTODOS}

O experimento foi conduzido na Fazenda de Ensino, Pesquisa e Extensão - UNESP, Campus de Ilha Solteira, localizada no município de Selvíria/MS, com coordenadas geográficas aproximadas de $20^{\circ} 22^{\prime}$ de latitude e $51^{\circ} 22^{\prime}$ de longitude, com altitude de $335 \mathrm{~m}$, temperatura média de $23,6^{\circ} \mathrm{C}$, precipitação total de aproximadamente 1370 $\mathrm{mm}$ por ano e evapotranspiração potencial de $1226 \mathrm{~mm}$. O solo utilizado é um LATOSSOLO VERMELHO Distroférrico típico (Embrapa, 2006), anteriormente ocupado pela cultura de trigo (Triticum aestivum L.) e braquiária (Brachiaria decumbens Stapf.), que apresentou inicialmente as seguintes características químicas (0,00-0,20 m): $\mathrm{pH}\left(\mathrm{CaCl}_{2}\right), 4,7 ; \mathrm{MO}, 27 \mathrm{~g} \mathrm{dm}^{-3}$; $\mathrm{P}_{\text {resina }}, 26 \mathrm{mg} \mathrm{dm}^{-3} ; \mathrm{K}, 2,8 ; \mathrm{Ca}, 13 ; \mathrm{Mg}, 11 ; \mathrm{H}+\mathrm{Al}, 40 ; \mathrm{Al}, 3$; SB 26,8; T 65,8 $\mathrm{mmol}_{\mathrm{c}} \mathrm{dm}^{-3}$ e V, $41 \%$.

O preparo do solo foi realizado com dessecação da cultura anterior (glifosato - 3,0 L p.c. ha ${ }^{-1}$ ) e roçagem mecânica, com posterior semeadura direta (outubro/2006) das cultivares de arroz para terras altas BRSMG Curinga e IAC 202. A cultivar de arroz BRSMG Curinga apresenta ciclo médio de 132 dias, enquanto a cultivar de arroz IAC 202 possui ciclo de 87 dias, podendo haver variações no ciclo de florescimento e maturação, em virtude da época de semeadura. Utilizou-se espaçamento de $0,34 \mathrm{~m}$ entrelinhas e densidade de semeadura de 70 sementes viáveis $\mathrm{m}^{-1}$. Cada parcela foi constituída por 5 linhas de $5 \mathrm{~m}$ de comprimento e, tendo como área útil, as 3 linhas centrais, desprezando $0,5 \mathrm{~m}$ em cada extremidade. As irrigações foram realizadas por meio de um sistema pivô central, em turnos e quantidades de água de acordo com os estádios fenológicos e necessidade hídrica da cultura.

As adubações com $\mathrm{P}_{2} \mathrm{O}_{5}$ e $\mathrm{K}_{2} \mathrm{O}$ foram baseadas na análise do solo e na tabela de recomendação de adubação para a cultura do arroz, para o Estado de São Paulo, conforme descrito em Raij et al. (1997), utilizando $250 \mathrm{~kg}$ ha $^{-1}$ da fórmula 04-30-16.

O delineamento estatístico utilizado foi o de blocos ao acaso, em um esquema fatorial $5 \times 3 \times 2 \times 2$, sendo os tratamentos constituídos da aplicação de cinco doses de $\mathrm{N}\left(0,50,100,150\right.$ e $\left.200 \mathrm{~kg} \mathrm{ha}^{-1}\right)$, utilizando-se três fontes de $\mathrm{N}$ (sulfonitrato de amônio (entec) - 26\% de N, apresentando grânulos com inibidor de nitrificação; sulfato de amônio e uréia), aplicados, totalmente, na semeadura (outubro/2006) ou em cobertura na fase do perfilhamento (novembro/2006), nas cultivares de arroz BRSMG Curinga e IAC 202, com quatro repetições.

Foram realizadas as seguintes avaliações: teor de $\mathrm{N}$ foliar - foram coletadas 30 folhas bandeira de arroz, ao acaso, no início do florescimento e analisadas conforme metodologia descrita em Malavolta et al. (1997); altura de plantas - a média foi obtida pela medida de 10 plantas ao acaso, por parcela, tendo-se considerado a distância entre a superfície do solo e o ápice da panícula, por ocasião da colheita; número de panículas $\mathrm{m}^{-2}$ - foi obtido contando-se as panículas em $1 \mathrm{~m}$ da área útil da parcela e os dados transformados em $\mathrm{m}^{2}$; número e massa de espiguetas granadas panícula $^{-1}$ - foram coletadas 20 panículas de arroz por parcela, ao acaso, dentro da área útil, para contagem e pesagem dos grãos e obtenção da média; massa de 100 grãos - foi determinada em coleta ao acaso com pesagem de duas amostras de 100 grãos de cada parcela (13\% base úmida); produtividade de grãos - obtida com a colheita de três linhas centrais de cada parcela, desprezando-se $0,5 \mathrm{~m}$ de cada extremidade, seguida de trilha mecânica. Os grãos obtidos foram pesados, e os dados transformados para $\mathrm{kg}$ ha $^{-1}$ ( $13 \%$ base úmida).

O Sistema de Análise Estatística - SANEST (Zonta et al., 1987) foi utilizado para a realização das análises de variância. O teste de Tukey ao nível de 5\% de probabilidade foi usado para comparar as médias das cultivares de arroz, assim como as fontes nitrogenadas e as épocas de aplicação. Para as doses de nitrogênio aplicaram-se análises de regressão.

\section{RESULTADOS E DISCUSSÃO}

Houve diferenças significativas entre cultivares em todas as variáveis analisadas, exceto para o teor de $\mathrm{N}$ foliar (Tabela 1). Os teores foliares apresentaram-se próximos aos adequados (Raij et al., 1997). A cultivar 
IAC 202 foi $8 \mathrm{~cm}$ mais alto que o BRSMG Curinga e apresentou maior número de grãos por panícula e maior massa de grãos por panícula, entretanto, a cultivar BRSMG Curinga apresentou maior número de panículas por $\mathrm{m}^{2}$ e maior massa de 100 grãos, resultando em maior produtividade.

Pela análise do número de panículas $\mathrm{m}^{-2}$ (Tabela 1$)$, ficou evidenciada a maior capacidade de perfilhamento da cultivar BRSMG Curinga, que também apresentou maior massa de 100 grãos e uma produtividade significativamente maior que a cultivar IAC 202. Por outro lado, a cultivar IAC 202 apresentou maior número e massa de espiguetas granadas panícula ${ }^{-1}$.

As épocas de aplicação não influenciaram nenhuma das avaliações, demonstrando que as fontes podem ser aplicadas totalmente na semeadura ou em cobertura (Tabela 1). Esse comportamento, deve-se ao fato do experimento ter sido irrigado logo após as adubações, não ocorrendo perdas significativas de $\mathrm{NH}_{3}$ proveniente da uréia. Marzari et al. (2005) também não encontraram diferenças significativas para épocas de aplicação de $\mathrm{N}$ na cultura do arroz. Por outro lado, Pinheiro (1982) e Santos et al. (1986) obtiveram maiores produtividades quando o $\mathrm{N}$ foi aplicado em cobertura, em sistema convencional de preparo do solo.

As fontes de $\mathrm{N}$ não diferiram significativamente para as variáveis analisadas, assim como ocorreu no trabalho de Javarez Junior et al. (1991) que também estudaram o efeito de doses e fontes de $\mathrm{N}$ (sulfato de amônio e uréia) para produtividade de grãos de arroz. A não diferença entre as fontes de $\mathrm{N}$ pode ser atribuída ao fato da baixa perda de amônia por volatilização com a aplicação de uréia, já que o pH do solo se encontrava baixo $(\mathrm{pH} \mathrm{CaCl}=4,7)$ e da irrigação logo após a aplicação dos fertilizantes nitrogenados. Já, no caso do sulfonitrato de amônio (entec), as temperaturas superiores a $25^{\circ} \mathrm{C}$ durante o período de condução do trabalho prejudicaram a inibição da nitrificação, uma vez que, segundo o fabricante desse fertilizante, a temperatura ideal para tal inibição é de $20^{\circ} \mathrm{C}$.

As doses de $\mathrm{N}$ influenciaram, praticamente, todas as variáveis analisadas, com exceção da massa de 100 grãos (Tabela 1). O número de panículas $\mathrm{m}^{-2}$, o número de espiguetas granadas panícula ${ }^{-1} \mathrm{e}$ a produtividade de grãos apresentaram ajuste quadrático com as doses de $\mathrm{N}$, enquanto as outras variáveis apresentaram ajuste linear.

Os teores de $\mathrm{N}$ foliar mostraram-se crescentes com o incremento das doses, estando dentro da faixa considerada como adequada (27-35 $\mathrm{g} \mathrm{de} \mathrm{N} \mathrm{kg}^{-1} \mathrm{MS}$, segundo Raij et al. (1997), para as doses de $\mathrm{N}$ acima de 50 $\mathrm{kg} \mathrm{ha}^{-1} \mathrm{de} \mathrm{N}$. Esse resultado foi decorrente do aumento da disponibilidade de $\mathrm{N}$, suficiente para elevar a concentração do elemento no tecido vegetal.

Ocorreu também, aumento na altura de plantas com o fornecimento de doses crescentes de $\mathrm{N}$, o que assemelhou-se ao verificado por Fageria \& Wilcox (1977) e Lopes et al. (1996). Já Mauad et al. (2003) verificaram a redução na altura de planta com o aumento das doses de $\mathrm{N}$. Isso deve-se ao fato de que o efeito do $\mathrm{N}$ na altura da planta depende não só da dose de $\mathrm{N}$, mas sim de outros fatores como o cultivar utilizado, luminosidade, temperatura e umidade.

O número de panículas $\mathrm{m}^{-2} \mathrm{e}$ o número de espiguetas granadas panícula ${ }^{-1}$ (Tabela 1) aumentaram com o aumento das doses de $\mathrm{N}$ até $128 \mathrm{~kg} \mathrm{ha}^{-1}$ e $172 \mathrm{~kg}$ $\mathrm{ha}^{-1}$, respectivamente, assim como ocorreu nos trabalhos de Stone \& Silva (1998), Husain \& Sharma (1991) e Mauad et al. (2003), que verificaram menor valor para o número de panículas $\mathrm{m}^{-2}$ na ausência de $\mathrm{N}$, pois, esse nutriente estimula o perfilhamento e aumenta o número de panículas área $^{-1}$. O número total de espiguetas granadas é dependente da translocação de carboidratos, que é influenciado por fatores genéticos e condições do ambiente, assim como níveis de nitrogênio, durante a fase reprodutiva. Assim, há necessidade de se utilizar doses adequadas de $\mathrm{N}$, pois o número de espiguetas se relaciona com a produtividade de grãos. Também, Campello Junior (1985) e Fornasieri Filho \& Fornasieri (1993) observaram que a adubação nitrogenada proporcionou aumento no número de panículas $\mathrm{m}^{-2}$, e no número de espiguetas, respectivamente. Já Alvarez et al. (2002) e Arf et al. (2003) não verificaram efeito da adubação nitrogenada em cobertura nas características agronômicas e produtivas em cultivares de arroz, demonstrando que a resposta da cultura ao $\mathrm{N}$ depende do cultivar, do manejo, do solo e clima.

Ocorreu aumento na massa de espiguetas granadas com o incremento nas doses de $\mathrm{N}$, o que também foi constatado por Fornasieri Filho \& Fornasieri (1993). O valor da massa de 100 grãos não apresentou diferenças significativas com relação às doses de $\mathrm{N}$ aplicadas, o que não ocorreu com os dados obtidos por Santos et al. (1986) e Buzetti et al. (2006), que constataram que as doses crescentes de $\mathrm{N}$ reduziram a massa de 100 grãos, podendo ser decorrente de uma melhor granação e, portanto, efeito de competição entre os grãos.

A dose de $122 \mathrm{~kg}$ de $\mathrm{N} \mathrm{ha}^{-1}$ proporcionou a maior produtividade, constatando-se um decréscimo com a utilização de doses acima desse valor. Isso se deve ao fato 
de que altas doses de $\mathrm{N}$ estimulam o perfilhamento e a formação de novas folhas, causando um autosombreamento, condição esta favorável à competição e queda na produtividade (Barbosa Filho, 1987; Stone et al., 1999). Em razão do sombreamento há uma diminuição da área fotossinteticamente ativa da planta, não havendo, portanto, carboidratos suficientes para o enchimento de todas as espiguetas, tornando a produtividade menor. Lopes et al. (1996) também verificaram resposta ao N para a produtividade com doses de até $120 \mathrm{~kg}$ de $\mathrm{N} \mathrm{ha}^{-1}$. Para Bordin et al. (2003), Farinelli et al. (2004) e Buzetti et al. (2006), a dose que proporcionou produtividade máxima foi a de $80 \mathrm{~kg}$ de $\mathrm{N} \mathrm{ha}^{-1}, 75 \mathrm{~kg}$ de $\mathrm{N} \mathrm{ha}^{-1}$ e $100 \mathrm{~kg}$ de $\mathrm{N} \mathrm{ha}^{-1}$, respectivamente, enquanto que, para Freitas et al. (2001),
Mariot et al. (2003) e Meira et al. (2005), essa dose foi igual a $90 \mathrm{~kg}$ de $\mathrm{N} \mathrm{ha}^{-1}$. Já, Mauad et al. (2003) verificaram que aplicação de altas doses de $\mathrm{N}$ não refletiram em aumento na produtividade de grãos, mas sim, na redução, pois estimularam o perfilhamento, a formação de novas folhas, causando autossombreamento, condições favoráveis à doenças, acamamento e queda na produtividade. Segundo esses resultados, não há uma recomendação geral para aplicação de nitrogênio, devendo-se considerar outros fatores, como: cultivar, manejo do solo, clima, dentre outros. Contudo, pode-se constatar no presente trabalho e na maior parte da literatura, que a aplicação de $\mathrm{N}$ entre as doses de 75 a $120 \mathrm{~kg}$ de $\mathrm{N} \mathrm{ha}^{-1}$ proporcionou maiores produtividades de grãos.

Tabela 1 - Médias, teste de Tukey e diferenças significativas referentes ao teor de $\mathrm{N}$ foliar (N FOLIAR), altura de plantas (AP), número de panículas $\mathrm{m}^{-2}\left(\mathrm{PAN} \mathrm{M}^{-2}\right)$, número de espiguetas granadas panícula-1 ${ }^{-1}$ GRA PAN $\left.{ }^{-1}\right)$, massa de espiguetas granadas panícula ${ }^{-1}\left(\mathrm{MASSA} \mathrm{PAN}^{-1}\right)$, massa de 100 grãos $(\mathrm{M} 100 \mathrm{G})$ e produtividade de grãos $(\mathrm{P}$ G) nas cultivares de arroz BRSMG Curinga e IAC 202 submetidos a diferentes doses, épocas de aplicação e fontes de nitrogênio. Selvíria/MS, 2006/07.

\begin{tabular}{|c|c|c|c|c|c|c|c|}
\hline & $\begin{array}{c}\text { N FOLIAR } \\
\left(\mathrm{g} \mathrm{kg}^{-1}\right)\end{array}$ & $\begin{array}{l}\text { AP } \\
(\mathrm{cm})\end{array}$ & PAN M $^{-2}$ & $\begin{array}{c}\text { GRA } \\
\text { PAN }^{-1}\end{array}$ & $\begin{array}{c}\text { MASSA } \\
\mathrm{PAN}^{-1}(\mathrm{~g})\end{array}$ & $\begin{array}{c}\text { M } 100 \mathrm{G} \\
(\mathrm{g})\end{array}$ & $\begin{array}{c}\mathrm{P} \mathrm{G} \\
\mathrm{kg} \mathrm{ha}^{-1}\end{array}$ \\
\hline Cultivar & & & & Médias & & & \\
\hline BRSMG Curinga & $27,67 \mathrm{a}$ & $97,75 \mathrm{~b}$ & $254 \mathrm{a}$ & $86,58 \mathrm{~b}$ & $2,32 \mathrm{~b}$ & $2,73 \mathrm{a}$ & $4010 \mathrm{a}$ \\
\hline IAC 202 & $26,70 \mathrm{a}$ & $105,66 \mathrm{a}$ & $222 b$ & $117,74 \mathrm{a}$ & $2,70 \mathrm{a}$ & $2,29 \mathrm{~b}$ & $3486 b$ \\
\hline DMS & 1,95 & 1,77 & 7,04 & 4,91 & 0,12 & 0,03 & 222 \\
\hline ÉPOCAS & & & & Médias & & & \\
\hline Semeadura & $27,76 \mathrm{a}$ & $101,05 \mathrm{a}$ & $242 \mathrm{a}$ & $101,61 \mathrm{a}$ & $2,50 \mathrm{a}$ & $2,51 \mathrm{a}$ & $3712 \mathrm{a}$ \\
\hline Cobertura & $26,60 \mathrm{a}$ & $102,36 \mathrm{a}$ & $235 \mathrm{a}$ & $102,72 \mathrm{a}$ & $2,52 \mathrm{a}$ & $2,51 \mathrm{a}$ & $3785 \mathrm{a}$ \\
\hline FONTES & & & & Médias & & & \\
\hline Entec & 28,13 a & $102,67 \mathrm{a}$ & $239 a$ & $105,64 \mathrm{a}$ & $2,58 \mathrm{a}$ & $2,50 \mathrm{a}$ & $3784 a$ \\
\hline Sulf. amônio & $27,32 \mathrm{a}$ & $101,49 \mathrm{a}$ & $237 \mathrm{a}$ & 100,95 a & $2,46 \mathrm{a}$ & $2,48 \mathrm{a}$ & $3742 \mathrm{a}$ \\
\hline Uréia & 26,09 a & $100,96 \mathrm{a}$ & $239 \mathrm{a}$ & 99,90 a & $2,48 \mathrm{a}$ & $2,55 \mathrm{a}$ & 3719 a \\
\hline DMS & 2,87 & 2,60 & 10,33 & 7,20 & 0,18 & 0,08 & 325 \\
\hline DOSES & & & & Médias & & & \\
\hline $0 \mathrm{~kg} / \mathrm{ha}$ & $23,42^{(1)}$ & $93,44^{(2)}$ & $212^{(3)}$ & $88,21^{(4)}$ & $2,18^{(5)}$ & 2,52 & $2816^{(6)}$ \\
\hline $50 \mathrm{~kg} / \mathrm{ha}$ & 26,34 & 97,20 & 247 & 102,83 & 2,50 & 2,51 & 3981 \\
\hline $100 \mathrm{~kg} / \mathrm{ha}$ & 27,36 & 100,96 & 245 & 102,25 & 2,53 & 2,51 & 4122 \\
\hline $150 \mathrm{~kg} / \mathrm{ha}$ & 29,27 & 104,73 & 245 & 108,94 & 2,65 & 2,51 & 4064 \\
\hline $200 \mathrm{~kg} / \mathrm{ha}$ & 29,53 & 108,49 & 242 & 108,58 & 2,68 & 2,50 & 3760 \\
\hline
\end{tabular}

Médias seguidas de letras iguais, na mesma coluna, não diferem entre si pelo teste de Tukey a 5\%.

(1) $\mathrm{Y}=24,1517+0,0303 \mathrm{~N}$

(2) $\mathrm{Y}=93,4375+0,0752 \mathrm{~N}$

(3) $\mathrm{Y}=215,5214+0,5473 \mathrm{~N}-0,0021 \mathrm{~N}^{2}$

(4) $\mathrm{Y}=89,5506+0,2233 \mathrm{~N}-0,00065 \mathrm{~N}^{2}$

(5) $\mathrm{Y}=2,2739+0,0023 \mathrm{~N}$

(6) $\mathrm{Y}=2906,0280+21,8642 \mathrm{~N}-0,08960 \mathrm{~N}^{2}$
$\mathrm{R}^{2}=0,93$
$\mathrm{R}^{2}=0,78$
$\mathrm{R}^{2}=0,84$
$\mathrm{R}^{2}=0,91$
$\mathrm{R}^{2}=0,85$
$\mathrm{R}^{2}=0,94$

$\mathrm{PM}=128 \mathrm{~kg} \mathrm{ha}^{-1}$ $\mathrm{PM}=172 \mathrm{~kg} \mathrm{ha}^{-1}$

$\mathrm{PM}=122 \mathrm{~kg} \mathrm{ha}^{-1}$ 
Houve correlação significativa entre o número de espiguetas granadas panícula ${ }^{-1}(\mathrm{r}=0,63 * *)$, massa de espiguetas granadas panícula ${ }^{-1}\left(\mathrm{r}=0,61^{* *}\right)$, panículas $\mathrm{m}^{-2}$ $(\mathrm{r}=0,72 * *)$ e $\mathrm{N}$ foliar $(\mathrm{r}=0,52 * *)$, em relação à produtividade. Nesse sentido, seria interessante adotar práticas que estimulassem o aumento dessas variáveis, para obtenção de maiores produtividades.

\section{CONCLUSÕES}

As doses de $\mathrm{N}$ aumentaram o teor de $\mathrm{N}$ foliar, a altura de plantas, o número de panículas $\mathrm{m}^{-2}$, o número e massa de espiguetas granadas panícula ${ }^{-1}$ e a produtividade de grãos.

A cultivar BRSMG Curinga apresentou maior produtividade, com média de $4010 \mathrm{~kg} \mathrm{ha}^{-1}$, alcançada com a utilização da dose $122 \mathrm{~kg}$ de $\mathrm{N} \mathrm{ha}^{-1}$, independente da fonte utilizada e da época de aplicação.

\section{REFERÊNCIAS BIBLIOGRÁFICAS}

ALVAREZ, A.C.C.; ARF, O.; PEREIRA, J.C. dos R.; BUZETTI, S. Comportamento de cultivares de arroz (Oryza sativa L.) irrigado por aspersão em função da aplicação de diferentes doses de nitrogênio em cobertura. In: CONGRESSO DA CADEIA PRODUTIVA DE ARROZ, 1.; REUNIÃO NACIONAL DE PESQUISA DE ARROZ - RENAPA, 7., 2002, Florianópolis. Anais... Santo Antônio de Goiás: Embrapa Arroz e Feijão, 2002. p.526-529.

ARF, O.; RODRIGUES, R.A.F.; CRUSCIOL, C.A.C.; SÁ, M.E.; BUZETTI, S. Manejo do solo e adubação nitrogenada em cobertura no comportamento de cultivares de arroz de terras altas irrigados por aspersão. Scientia Agrícola, Piracicaba, v.60, n.2, p.345-352, 2003.

BARBOSA FILHO, M.P. Nutrição e adubação do arroz: sequeiro e irrigado. Piracicaba: Associação Brasileira para Pesquisa da Potassa e do Fosfato, 1987. 129p. (Boletim técnico, 9).

BORDIN, L.; FARINELLI, R.; PENARIOL, F.G.; FORNASIERI FILHO, D. Sucessão de cultivo de feijãoarroz com doses de adubação nitrogenada após adubação verde, em plantio direto. Bragantia, Campinas, v.62, p.235-241, 2003.

BUZETTI, S.; BAZANINI, G.C.; FREITAS, J.G.; ANDREOTTI, M.; ARF, O.; SÁ, M.E.; MEIRA, F.A. Resposta de cultivares de arroz a doses de nitrogênio e do regulador de crescimento cloreto de clormequat. Pesquisa Agropecuária Brasileira, Brasília, v.41, n.12, p.1731-1737, 2006.

CAMPELLO JUNIOR, J.O. Avaliação da capacidade de extração de água do solo pelo arroz de sequeiro (Oriza sativa L.) sob diferentes doses de nitrogênio. 1985. 127p. Tese (Doutorado)-Escola Superior de Agricultura "Luis de Queiroz”, Piracicaba, 1985.

EMPRESA BRASILEIRA DE PESQUISA

AGROPÉCUÁRIA. Centro Nacional de Pesquisa de

Solos. Sistema brasileiro de classificação de solos. 2.ed.

Rio de Janeiro, 2006. 306p.

FAGERIA, N.K.; SLATON, N.A.; BALIGAR, V.C. Nutrient management for improving lowland rice productivity and sustainability. Advance Agricola, v.80, p.63-152, 2003.

FAGERIA, N.K.; WILCOX, G.E. Influência de nitrogênio e fósforo no crescimento do arroz. Lavoura Arrozeira, v.30, n.301, p.24-28, 1977.

FARINELLI, R.; PENARIOL, F.G.; FORNASIERI FILHO, D.; BORDIN, L. Características agronômicas de arroz de terras altas sob plantio direto e adubação nitrogenada e potássica. Revista Brasileira de Ciência do

Solo, Campinas, v.28, n.3, p.447-454, 2004.

FORNASIERI FILHO, D.; FORNASIERI, J.L. Manual da cultura do arroz. Jaboticabal: FUNEP, 1993. 221p.

FREITAS, J.G.; AZZINI, L.E.; CANTARELLA, H.; BASTOS, C.R.; CASTRO, L.H.S.M. de; GALLO, P.B.; FELÍCIO, J.C. Resposta de cultivares de arroz irrigado ao nitrogênio. Scientia Agricola, Piracicaba, v.58, p.573-579, 2001.

HUSAIN, S.M.; SHARMA, U.C. Response of rice to nitrogen fertilizer in acidic soil of Nagaland. Journal Agricola Science, v.61, p.662-664, 1991.

JAVAREZ JUNIOR, A.; MORAIS, H.A.; SÁ, M.E.; BUZETTI, S.; ARF, O. Efeitos de doses e fontes de nitrogênio em cobertura sobre a produção de arroz. Lavoura arrozeira. In: CONGRESSO DE INICIAÇÃO CIENTÍFICA DA UNESP, 3., 1991, Jaboticabal. Anais... Jaboticabal: FCA/UNESP, 1991. p.89. 
LOPES, S.I.G.; LOPES, M.S.; MACEDO, V.R.M. Curva de resposta à aplicação de nitrogênio para quatro genótipos de arroz irrigado. Lavoura Arrozeira, v.49, p.3-6, 1996.

MALAVOLTA, E.; VITTI, G.C.; OLIVEIRA, S.A. Avaliação do estado nutricional das plantas: princípios e aplicações. 2.ed. Piracicaba: Potafos, 1997. 319p.

MARIOT, C.H.P.; SILVA, P.R.F.; MENEZES, V.G.; TEICHMANN, L.L. Resposta de duas cultivares de arroz irrigado à densidade de semeadura e à adubação nitrogenada. Pesquisa Agropecuária Brasileira, Brasília, v.38, n.2, p.233-241, 2003.

MARUMOTO, T. Microbial nitrogen fixation and its availability to rice plants as revealed with the use of $15 \mathrm{~N}$ in Japan. Japan Agricultural Research Quarterly, Yatabe, v.20, n.2, p.108-114, 1986.

MARZARI, V.; MARCHEZAN, E.; SILVA, L.S.; RANNO, S.K.; SANTOS, F.M.; CAMARGO, E.R. Épocas de aplicação do fertilizante nitrogenado no sistema convencional de semeadura de arroz irrigado. Ciência Rural, Santa Maria, v.35, n.5, p.1190-1193, 2005.

MAUAD, M.; GRASSI FILHO, H.; CRUSCIOL, C.A.C.; CORREAA, J.C. Teores de silício no solo e na planta de arroz de terras altas com diferentes doses de adubação silicatada e nitrogenada. Revista Brasileira de Ciência do Solo, Campinas, v.27, n.5, p.867-873, 2003.

MEIRA, F.A.; BUZETTI, S.; FREITAS, J.G.; ARF, O.; SÁ, M.E. de. Resposta de dois cultivares de arroz à adubação nitrogenada e tratamento foliar com fungicidas. Acta Scientiarum, Londrina, v.27, p.91-95, 2005 .

PINHEIRO, B.S. Deficiência hídrica em arroz de sequeiro. Goiânia: Embrapa/CNPAF, 1982. 16p. Relatório de projeto de pesquisa.

RAIJ, B. van; CANTARELLA, H.; QUAGGIO, J.A.; FURLANI, A.M.C. Recomendações de adubação e calagem para o estado de São Paulo. 2.ed. Campinas: Instituto Agronômico de Campinas, 1997. 285p.

SANTOS, A.B.; PRABHU, A.S.; AQUINO, A.R.L.; CARVALHO, J.R.P. Épocas, modos de aplicação e níveis de nitrogênio sobre brusone e produção de arroz de sequeiro. Pesquisa Agropecuária Brasileira, Brasília, v.21, n.7, p.697-707, 1986

STONE, L.F.; SILVA, J.G. Resposta do arroz de sequeiro à profundidade de aração, adubação nitrogenada e condições hídricas do solo. Pesquisa Agropecuária Brasileira, Brasília, v.33, p.891-897, 1998.

STONE, L.F.; SILVEIRA, P.M.; MOREIRA, J.A.A.; YOKOYAMA, L.P. Adubação nitrogenada em arroz sob irrigação suplementar por aspersão. Pesquisa Agropecuária Brasileira, Brasília, v.34, p.927-932, 1999.

ZONTA, E.P.; MACHADO, A.A.; SILVEIRA JUNIOR, P. Sistema de análise estatística para microcomputadores: manual de utilização. 2.ed. Pelotas: UFPel, 1987. 177p. 